\title{
What do dogs, ancient Romans, Linus Pauling, and mass spectrometry have in common? Early lung cancer and exhaled breath
}

\author{
Victor A. Ferraris, MD, PhD
}

\author{
From the Department of Surgery, University of Kentucky, Lexington, Ky. \\ Disclosures: Author has nothing to disclose with regard to commercial support. \\ Received for publication Sept 28, 2015; accepted for publication Sept 29, 2015; available ahead of print \\ Oct 21,2015 \\ Address for reprints: Victor A. Ferraris, MD, PhD, Department of Surgery, University of Kentucky, A301 \\ Kentucky Clinic, 740 S Limestone, Lexington, KY 40506-0284 (E-mail: ferraris@uky.edu). \\ J Thorac Cardiovasc Surg 2016;151:313-4 \\ $0022-5223 / \$ 36.00$ \\ Copyright (C) 2016 by The American Association for Thoracic Surgery \\ http://dx.doi.org/10.1016/j.jtcvs.2015.09.120
}

Fully half of patients who present with lung cancer have advanced-stage disease and very little chance of longterm survival. There has been little improvement in this dismal prognosis in the past 50 years. At present, the best chance of long-term cure from lung cancer is early detection. This makes things like searching for biomarkers to use as screening tools-possibly in exhaled volatile organic compounds (VOCs) — very attractive.

This is not a new idea. Ancient Roman practitioners used the smell of a person's breath to diagnose disease, a method that still holds true today. For example, diabetes results in a sweet, acetone odor to the breath, liver failure conveys a fish-like smell, and renal failure gives exhaled breath a urine-like smell. ${ }^{1}$ In the modern literature, highly trained dogs have been shown to be able to detect various stages of lung cancer and breast cancer by smelling exhaled breath at rates almost as good as those gleaned from mass spectrometry. ${ }^{2}$ In 1971, Linus Pauling (the Nobel laureate) and colleagues, ${ }^{3}$ using a gas chromatograph, measured 250 different compounds in human breath samples. Since then, Phillips and colleagues ${ }^{4}$ have identified more than 3000 compounds in exhaled breath of patients with lung cancer.

VOCs are produced by virtually all metabolic processes of the body and are exhaled via the lungs most commonly. ${ }^{5}$ Because exhaled VOCs are either derived from the respiratory tract itself or are filtered through the lungs from the circulation, they reflect a wide variety of physiologic and pathologic processes and can be especially useful biomarkers for the diagnosis and monitoring of pulmonary diseases. As simple as this concept sounds, there are problems with its application. Exhaled biomarkers are likely to be affected by multiple comorbid conditions, ${ }^{6}$ and certain interventions like a surgical procedure can alter the composition of exhaled gases. ${ }^{7}$ An ideal biomarker should reflect a specific disease state-like prostatespecific antigen reflects prostate cancer risk and carcinoembryonic antigen reflects the presence of certain cancers. The key question addressed in the article by Schumer and

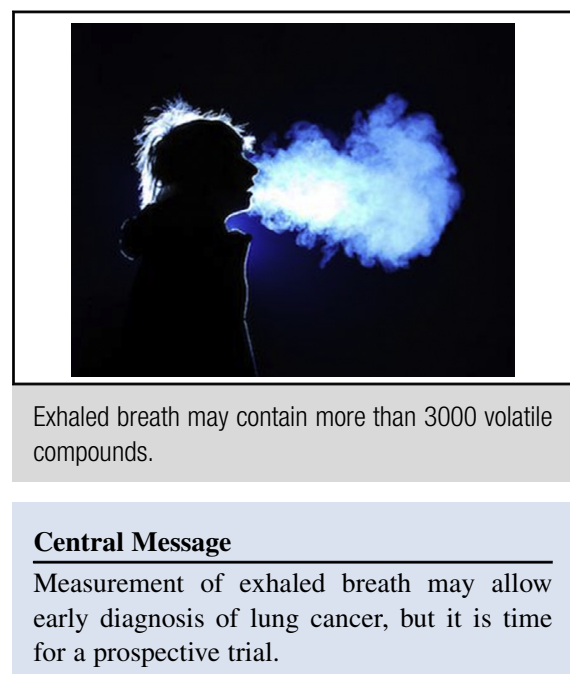

See Article page 1517 in the December issue.

See Editorial Commentary page 1525 in the December issue.

colleagues $^{8}$ is whether or not measurement of exhaled VOCs provide a means of identifying patients with earlystage lung cancer. The article is the fourth in a series that describes analyses of exhaled gases to detect carbonyl compounds. ${ }^{9-11}$ Each successive article describes analyses of various groups of patients with and without lung cancer. They first used their analysis method to try to differentiate patients with lung cancer from those with benign disease. In the present article, ${ }^{8}$ they lowered their detection threshold and increased the number of patients sampled to assess the potential of their analysis for use as a screening tool to replace/supplement screening with computed tomography.

I wonder about the sampling process for measuring carbonyl compounds in exhaled gases. In their earlier work, the authors tried variations in the sampling process. It is important to understand noncancer confounding factors that alter carbonyl compounds in exhaled breath. Would it help to administer bronchodilators before sampling the exhaled gases? Are there other interventions that might optimize measurement of these exhaled compounds? Further, I wonder about the need to explore other sources of carbonyl compounds in exhaled gases? Do electronic cigarettes contain carbonyl compounds that might interfere 
with testing? Similarly, certain smokers may have higher levels of these compounds in their exhaled air. There may be more preliminary work that needs to be done to improve the specificity of the authors' assay method.

The work by Schumer colleagues ${ }^{8}$ implies that lung cancer induces metabolic changes in the malignant lung tissue that results in production and exhalation of VOCs. Because there may be as many as 3000 volatile compounds in exhaled breath, identifying and measuring the specific and sensitive exhaled biomarkers that reflect lung cancer is no small task. There are different techniques for measuring VOCs in exhaled breath. ${ }^{5}$ These published techniques use diverse technology, including ion mobility spectrometry, quartz microbalances, carbon polymer chemoresistors, colorimetric analyzers, and gold particle nanosensors. ${ }^{5}$ One promising and specific method for measuring exhaled VOCs involves chemical binding of exhaled carbonyl compounds to a silicon microreactor array and subsequent quantitation using gas chromatography/ mass spectrometry as described by Schumer and colleagues. $^{8}$

A key feature any screening tool is how sure can one be that an abnormal value justifies an invasive procedure to confirm the diagnosis. The authors suggest a range of elevated levels of carbonyl compounds that provide various sensitivity and specificity. Some justification for using 1.5 standard deviations above control as the cutoff seems reasonable and provides a clearer picture of how useful this test might be.

Schumer and colleagues ${ }^{8}$ suggest that their analysis technique is a low-cost option. That assertion remains to be seen. To test the cost-effectiveness of their analysis methodology, the authors need to consider all of the components of cost. There is a fairly high cost of equipment, including the purchase of mass spectrometer. This fixed cost is a 1-time purchase cost that should be amortized over the life of the machine. It is likely that there are other nonfixed costs related to sampling (eg, purchase of sampling equipment to harvest expired air) required for these analyses. No matter, the true cost of this type of analysis will add to the cost of diagnosing lung cancer. This additional cost might be offset by avoiding an operation for resection of benign nodules, but some hypothetical cost analyses would help us understand potential benefits of the process involving sampling of exhaled gases. Further cost-offset might be achieved by using exhaled breath analysis for determining response to therapy in patients with advanced-stage lung cancer.

The authors suggest that measurement of exhaled carbonyl compounds might be a screening tool for lung cancer in a similar manner to prostate-specific antigen for prostate cancer or carcinoembryonic antigen levels for colon cancer. I wonder if the authors thought this through to a conclusion? How many people would have to be screened to detect a single cancer? What would be the frequency of sampling for at-risk patients? What degree of specificity and sensitivity justifies more aggressive interventions? Answers to these questions will help surgeons understand the role of this analysis method in the process of identifying early lung cancer. The authors ${ }^{8}$ point out that it is time for a prospective multiinstitutional trial to answer some of these questions. It seems that the authors have all the preliminary data needed to justify this type of study. I hope they will pursue this avenue of investigation. It may be the best thing we can do to limit the continued dismal prognosis of lung cancer.

\section{References}

1. Buszewski B, Kesy M, Ligor T, Amann A. Human exhaled air analytics: biomarkers of diseases. Biomed Chromatogr. 2007;21:553-66.

2. McCulloch M, Jezierski T, Broffman M, Hubbard A, Turner K, Janecki T. Diagnostic accuracy of canine scent detection in early- and late-stage lung and breast cancers. Integr Cancer Ther. 2006;5:30-9.

3. Pauling L, Robinson AB, Teranishi R, Cary P. Quantitative analysis of urine vapor and breath by gas-liquid partition chromatography. Proc Natl Acad Sci U S A. 1971;68:2374-6.

4. Phillips M, Gleeson K, Hughes JM, Greenberg J, Cataneo RN, Baker L, et al. Volatile organic compounds in breath as markers of lung cancer: a cross-sectional study. Lancet. 1999;353:1930-3.

5. Dent AG, Sutedja TG, Zimmerman PV. Exhaled breath analysis for lung cancer. J Thorac Dis. 2013;5(Suppl 5):S540-50.

6. van der Schee MP, Paff T, Brinkman P, van Aalderen WM, Haarman EG, Sterk PJ. Breathomics in lung disease. Chest. 2015;147:224-31.

7. Boshier PR, Mistry V, Cushnir JR, Kon OM, Elkin SL, Curtis S, et al. Breath metabolite response to major upper gastrointestinal surgery. J Surg Res. 2015; 193:704-12.

8. Schumer EM, Trivedi JR, van Berkel V, Black MC, Li M, Fu X, et al. High sensitivity for lung cancer detection by analysis of exhaled carbonyl compounds. J Thorac Cardiovasc Surg. 2015;150:1517-24.

9. Li M, Yang D, Brock G, Knipp RJ, Bousamra M, Nantz MH, et al. Breath carbonyl compounds as biomarkers of lung cancer. Lung Cancer. 2015;90:92-7.

10. Fu XA, Li M, Knipp RJ, Nantz MH, Bousamra M. Noninvasive detection of lung cancer using exhaled breath. Cancer Med. 2014;3:174-81.

11. Bousamra M II, Schumer E, Li M, Knipp RJ, Nantz MH, van Berkel V, et al. Quantitative analysis of exhaled carbonyl compounds distinguishes benign from malignant pulmonary disease. J Thorac Cardiovasc Surg. 2014;148: 1074-80; discussion 80-1. 